\title{
Increased hypolipidemic benefits of cis-9, trans-11 conjugated linoleic acid in combination with trans-11 vaccenic acid in a rodent model of the metabolic syndrome, the JCR:LA-cp rat
}

M Miriam Jacome-Sosa ${ }^{1,2,3}$, Jing Lu, ${ }^{1,2,3}$, Ye Wang ${ }^{1,2,3}$, Megan R Ruth ${ }^{2,3}$, David C Wright ${ }^{2,3}$, Martin J Reaney ${ }^{4}$, Jianheng Shen ${ }^{4}$, Catherine J Field ${ }^{2,3}$, Donna F Vine ${ }^{1,2,3}$, Spencer D Proctor ${ }^{1,2,3^{*}}$

\begin{abstract}
Background: Conjugated linoleic acid (cis-9, trans-11 CLA) and trans-11 vaccenic acid (VA) are found naturally in ruminant-derived foods. CLA has been shown to have numerous potential health related effects and has been extensively investigated. More recently, we have shown that VA has lipid-lowering properties associated with reduced hepatic lipidogenesis and chylomicron secretion in the JCR:LA-cp rat. The aim of this study was to evaluate potential additional hypolipidemic effects of purified forms of CLA and VA in an animal model of the metabolic syndrome (the JCR:LA-cp rat).
\end{abstract}

Methods: Twenty four obese JCR:LA-cp rats were randomized and assigned to one of three nutritionally adequate iso-caloric diets containing $1 \% \mathrm{w} / \mathrm{w}$ cholesterol and $15 \% \mathrm{w} / \mathrm{w}$ fat for $16 \mathrm{wk}: 1)$ control diet (CD), 2) 1.0\% w/w cis-9, trans-11 CLA (CLA), 3) 1.0\% w/W VA and 1\% w/w cis-9, trans-11 CLA (VA+CLA). Lean rats were fed the CD to represent normolipidemic conditions.

Results: Fasting plasma triglyceride (TG), total cholesterol and LDL-cholesterol concentrations were reduced in obese rats fed either the CLA diet or the VA+CLA diet as compared to the obese control group ( $p<0.05, p<$ $0.001 ; p<0.001, p<0.01 ; p<0.01, p<0.001$, respectively). The VA+CLA diet reduced plasma TG and LDLcholesterol to the level of the normolipidemic lean rats and further decreased nonesterified fatty acids compared to the CLA diet alone. Interestingly, rats fed the VA+CLA diet had a higher food intake but lower body weight than the CLA fed group $(P<0.05)$. Liver weight and TG content were lower in rats fed either CLA $(p<0.05)$ or VA $+C L A$ diets $(p<0.001)$ compared to obese control, consistent with a decreased relative protein abundance of hepatic acetyl-CoA carboxylase in both treatment groups $(P<0.01)$. The activity of citrate synthase was increased in liver and adipose tissue of rats fed, CLA and VA+CLA diets $(p<0.001)$ compared to obese control, suggesting increased mitochondrial fatty acid oxidative capacity.

Conclusion: We demonstrate that the hypolipidemic effects of chronic cis-9, trans-11 CLA supplementation on circulating dyslipidemia and hepatic steatosis are enhanced by the addition of VA in the JCR:LA-CP rat.

\section{Introduction}

Conjugated linoleic acid (CLA) is a term that refers to diverse positional and geometrical isomers of linoleic acid and its numerous health related effects have been extensively investigated. CLA was first described as a potent anti-carcinogenic component and more recently

* Correspondence: spencer.proctor@ualberta.ca

Full list of author information is available at the end of the article has been associated with improving dyslipidemia, insulin sensitivity and the pro-inflammatory state related to obesity and the metabolic syndrome [1,2]. However, some animal studies (specifically those using mouse models), in addition to a handful of clinical trials, have indicated that the major isomers found in CLA mixtures (cis-9, trans-11 CLA and trans-10, cis-12 CLA) are responsible for different physiological effects [1-10]. 
CLA is found naturally in ruminant-derived lipids and cis-9, trans-11 CLA is the major natural isoform, accounting for about $80-90 \%$ of the total CLA isomers [11]. Trans-11 vaccenic acid (VA) is the precursor to endogenous synthesis of the cis-9, trans-11 CLA isomer in rats [12,13] and humans [14], and is the predominant isomer of the total trans fatty acids found in ruminantderived fats such as dairy and meat products. We have shown previously that unlike industrially produced trans fatty acids, VA has lipid-lowering properties associated with reduced hepatic lipogenesis and chylomicron secretion in the obese and insulin resistant JCR:LA- $c p$ rat [15]. Interestingly, our observations indicate that VA has neutral effects under normolipidemic conditions and induces hypotriglyceridemic effects under conditions of dyslipidemia [16]. We also observed that VA supplementation for 16 weeks had a greater potential to influence lipoprotein metabolism [15] compared to a shorter term feeding [16]. These findings are supported by several clinical [17-19] and animal studies [20-24] showing that dietary trans fats derived from ruminants have either neutral or beneficial effects on cardiovascular disease risk factors compared to industrially produced trans fats.

As a result of the increasing evidence associating CLA and more recently VA with health benefits, there has been a growing interest to increase the concentrations of these natural trans fats in meat and dairy products [25-28]. Interestingly, both VA and CLA (cis-9, trans11) can account for more than $15 \%$ of the total fat in naturally enhanced dairy products [26] which could provide an additional health value to animal-derived fats. Consequently, in this study we hypothesized that chronic supplementation with both CLA and VA would enhance the lipid lowering effects to improve whole body lipid metabolism. Therefore, the aim of this study was to evaluate the effect of dietary supplementation with purified forms of both cis-9, trans-11 CLA and VA on impaired lipid metabolism in an established animal model of the metabolic syndrome, the JCR:LA- $c p$ rat.

\section{Materials and methods}

\section{Animals and diets}

All experimental procedures were approved by the University of Alberta Animal Ethics Committee and conducted in accordance with the Canadian Council on Animal Care. Twenty four male obese JCR:LA-cp rats $(c p / c p)$ were raised in our established breeding colony at the University of Alberta as previously described [29]. At 3 wk of age, rats were transferred from the isolated breeding colony areas to an individually ventilated caging environment (TecniplastTM, Exton PA, USA) and had access to a standard rat chow diet (5001, PMI Nutrition International) (see
Additional file 1). At 8 wk of age, rats $(\mathrm{n}=8)$ were randomized and assigned to one of three diets for 16 wk (control and experimental diets) and had free access to food and water. Age and weight matched lean littermates $(n=8)$ were fed the control diet to mimic cholesterol/high fat feeding under normolipidemic conditions. Food intake and body weight (BW) were monitored weekly throughout the study. At 23 wk of age, a meal tolerance test (MTT) as previously described [30], was performed in four randomly chosen rats from control and treatment groups in order to determine plasma glucose and insulin concentrations after a meal. We also performed an oral fat challenge test (OFC), as previously described [29] in four additional rats from each group. At the end of the treatment period (24 wk of age), rats were fasted overnight and anesthetized using isofluorane anesthesia. Plasma was sampled from the left ventricle and heart, liver and fat pads were excised, weighted and immediately frozen at $-80^{\circ} \mathrm{C}$ until analysis. Adipose fatty acid composition was measured from total triglyceride on the epidydimal fat pad as previously described [16].

Three iso-caloric diets were prepared with a constant polyunsaturated to saturated fatty acid ratio (P:S) of 0.4 . A control diet $(C D)$ was supplemented $(\mathrm{w} / \mathrm{w})$ with $1 \%$ cholesterol and contained $42 \%$ of energy from carbohydrate, $23.7 \%$ from protein and 34.3\% from fat. Experimental diets were prepared by adjusting the lipid composition of the CD to provide $1.0 \% \mathrm{w} / \mathrm{w}$ of cis -9 , trans-11 CLA alone (CLA), both $1 \%$ of VA and 1\% w/w of cis-9, trans-11 CLA (VA+CLA). Semi-purified cis-9, trans-11 CLA (G-c9t11 80:20) containing 59.8\% of cis-9, trans-11 CLA and $14.4 \%$ of trans-10, cis-12 CLA was kindly provided by Lipid Nutrition. The amount of CLA and VA $(1 \% \mathrm{w} / \mathrm{w})$ was chosen based on previous studies allowing for metabolic sufficiency while maintaining a normal dietary fatty acid proportion [15-17,31]. Purified VA was synthesized by a chemical alkali isomerisation from linoleic acid-rich vegetable oil [32]. The diet mixture was extruded into pellets, dried at $\mathrm{RT}^{\circ} \mathrm{C}$ and stored at $4^{\circ} \mathrm{C}$. Fatty acid composition of the three diets was confirmed by gas chromatograph analysis [28] of the fat blend samples (Table 1).

\section{Plasma biochemical components}

The concentration of biochemical parameters in fasting plasma from lean and obese groups were assessed using commercially available homogenous, enzymatic colorimetric assays. Triglyceride (TG) (Wako Pure Chemical Industries, catalog no. 998-40391, $0.01 \mathrm{mmol} / \mathrm{L} \mathrm{mini-}$ mum), Total cholesterol (TC) (Wako Pure Chemical Industries, catalog no. 993-00404, $0.002 \mathrm{mmol} / \mathrm{L}$ minimum), LDL cholesterol (LDL-C) (Wako Pure Chemical Industries, catalog no. 993-00404, 0.03-10.4 mmol/L) 
Table 1 Fatty acid composition (\% of total fatty acids) of control and experimental diets

\begin{tabular}{|c|c|c|c|}
\hline Fatty acid & Control diet (CD) & CLA diet & VA+CLA diet \\
\hline C16:0 & 9.1 & 8.5 & 9.1 \\
\hline C18:0 & 47.3 & 46.9 & 44.3 \\
\hline $18: 1 t-11$ (VA) & ND & ND & 5.6 \\
\hline $18: 1$ c-9 $(\mathrm{OA})$ & 17.3 & 11.4 & 10.5 \\
\hline $18: 1 c-11$ & ND & 0.5 & 0.5 \\
\hline C18:2 n6 (LA) & 23.3 & 23.4 & 20.4 \\
\hline C18:3 n3 (ALA) & 1.6 & 1.7 & 1.6 \\
\hline CLA c-9, t-11 & 0 & 5.2 & 3.9 \\
\hline CLA $t-10, c-12$ & ND & 1.1 & 0.8 \\
\hline other CLA & ND & 0.3 & 0.3 \\
\hline \multicolumn{4}{|l|}{ Summary } \\
\hline$\sum$ total SFA ${ }^{2}$ & 57.2 & 56.3 & 54.2 \\
\hline$\Sigma C 12: 0, C 14: 0, C 16: 0^{3}$ & 9.1 & 8.5 & 9.1 \\
\hline$\sum$ cis MUFA ${ }^{4}$ & 17.4 & 12.0 & 11.1 \\
\hline$\sum$ PUFA $^{5}$ & 25.0 & 25.1 & 22.0 \\
\hline$\sum n-6$ PUFA & 23.4 & 23.4 & 22.0 \\
\hline$\sum n-3$ PUFA & 1.6 & 1.7 & 1.6 \\
\hline $\mathrm{P} / \mathrm{S}$ ratio ${ }^{6}$ & 0.4 & 0.4 & 0.4 \\
\hline$\Sigma C L A$ & 0.0 & 6.6 & 5.0 \\
\hline
\end{tabular}

1. No detectable

${ }^{2}$ Sum of all saturated fatty acids

${ }^{3}$ Sum of lauric, myristic and palmitic acids

${ }^{4}$ cis MUFA, sum of all monounsaturated excepting trans fatty acids

${ }^{5}$ Sum of all polyunsaturated fatty acids excepting CLA

${ }^{6}$ Ratio of polyunsaturated to saturated fatty acids

and nonesterified fatty acids (NEFA) (HR Series NEFAHR, catalog no. 999-34691, Wako Diagnostics) were measured using direct colorimetric chemical enzymatic reactions. Plasma glucose was measured as per the glucose oxidase method (Diagnostic Chemical, catalog no. 220-32, 0.03-33.3 $\mathrm{mmol} / \mathrm{L}$ ) and plasma insulin was determined using commercially available enzymatic immunoassays for rodents (Ultrasensitive rat insulin ELISA, Mercodia, catalog no. 80-INSRTU-E01, 0.03-1.0 $\mathrm{pmol} / \mathrm{L}$ ). Samples were analyzed in triplicate using assay kits from a single lot and performed in one single batch.

\section{Tissue homogenization and hepatic TG}

Liver and adipose tissue samples $(0.5 \mathrm{~g})$ were homogenized in $200 \mu \mathrm{L}$ lysis buffer [PBS (pH 7.4) with $1.5 \%$ TritonX-100 and 1\% protease inhibitor cocktail (Sigma)] and and hepatic TG levels were determined by a commercially available enzymatic colorimetric assay (Wako Pure Chemical Industries, catalog no. 998-40391, 0.01 $\mathrm{mmol} / \mathrm{L}$ minimum), using an aliquot of the whole homogenate and adjusting by the protein concentration of the homogenate [15]. The remainder of the homogenate was centrifuged at $700 \mathrm{~g}$ for $15 \mathrm{~min}$ and the supernatant was collected and stored at $-80 \mathrm{C}$ for western blot and citrate synthase activity analysis.
Hepatic and adipose tissue citrate synthase activity Citrate synthase activity in liver and adipose tissue samples was determined using a commercially available kit from Sigma (catalog no. CS0720). The coefficient of variation of this assay in our laboratory is $<10 \%$. The citrate synthase activity was expressed as $\mu \mathrm{mol} / \mathrm{min} / \mathrm{g}$ protein.

\section{Relative protein abundance of lipogenic enzymes}

Hepatic acetyl-CoA carboxylase-1 (ACC-1) and fatty acid synthase (FAS) were determined by western blot analysis as described elsewhere [33] with few modifications [15]. ACC-1 and FAS relative abundance were normalized based on the respective $\beta$-actin protein mass (internal control).

\section{Statistical analysis}

Statistical analysis was performed using the Graph pad Prism software, version 4.0. Data was tested for normal distribution and one-way ANOVA followed by Tukey post-hoc tests were used to identify differences among both lean and obese controls and treatment groups (CLA and VA+CLA). Post-prandial glucose and insulin metabolism as well as post-prandial TG response were assessed by area under the curve (AUC) analysis. Fasting concentrations of these parameters were further subtracted from the total AUC to yield the incremental area under the curve (iAUC). Results are expressed as means \pm SEM and the level of significance was set at $\mathrm{p}<0.05$.

\section{Results}

Food intake, body weight and body composition

Obese rats fed the combination of VA+CLA showed increased food intake compared to those obese rats fed either the CD or CLA diet. Paradoxically, the VA+CLA fed rats showed reduced body weight $(p<0.001)$ compared to the CLA group (Table 2). Despite the higher body weight of rats fed the CLA diet as compared to obese control, no difference was observed in absolute and relative heart weights or fat pad deposition ( $p>$ 0.05 ), as measured by the amount of absolute and relative perirenal and inguinal fat pad weights compared with the obese rats fed the CD (Table 2). In contrast, feeding either the CLA or the VA+CLA diet resulted in a lower absolute liver weight by $15 \%$ and $26 \%$, respectively, and both diets reduced the ratio of liver weight to total body weight by $22 \%$ as compared to obese rats fed the $\mathrm{CD}(\mathrm{p}<0.001)$.

\section{Citrate synthase activity in liver and adipose tissue}

The activity of citrate synthase in liver and adipose tissue is shown in Figure 1. There was a higher $(\mathrm{p}<0.001)$ citrate synthase activity in liver and inguinal adipose 
Table 2 Food intake, body weight and body composition of rats in dietary groups

\begin{tabular}{|c|c|c|c|c|}
\hline & \multicolumn{4}{|c|}{ Dietary groups } \\
\hline & Lean control & Obese control & Obese CLA & Obese VA+CLA \\
\hline Food intake (g/day) & $19.7 \pm 0.3^{c}$ & $32.4 \pm 0.5^{b}$ & $31.4 \pm 0.6^{b}$ & $36.1 \pm 0.6^{* * * a}$ \\
\hline BW/16 wk (g) & $384 \pm 8.2^{c}$ & $646 \pm 9.3^{b}$ & $702 \pm 17.9^{\mathrm{a} *}$ & $624 \pm 9.5^{b}$ \\
\hline Heart (g) & $0.89 \pm 0.0^{b}$ & $1.19 \pm 0.0^{a}$ & $1.26 \pm 0.0^{\mathrm{a}}$ & $1.23 \pm 0.0^{\mathrm{a}}$ \\
\hline weight, \%BW & $0.23 \pm 0.0^{\mathrm{a}}$ & $0.18 \pm 0.0^{b}$ & $0.18 \pm 0.0^{b}$ & $0.20 \pm 0.0^{b}$ \\
\hline Liver (g) & $9.1 \pm 0.4 d$ & $23.1 \pm 0.7^{\mathrm{a}}$ & $19.7 \pm 0.6^{* * * b}$ & $17.2 \pm 0.3^{* * * c}$ \\
\hline weight, \%BW & $2.4 \pm 0.1^{c}$ & $3.6 \pm 0.1^{a}$ & $2.8 \pm 0.1^{* * * b}$ & $2.8 \pm 0.0^{* * * b}$ \\
\hline Perirenal FP' (g) & $1.3 \pm 0.1^{c}$ & $7.4 \pm 0.4^{\mathrm{ab}}$ & $8.6 \pm 0.8^{\mathrm{a}}$ & $6.7 \pm 0.4^{b}$ \\
\hline weight, \%BW & $0.33 \pm 0.0^{b}$ & $1.2 \pm 0.1^{\mathrm{a}}$ & $1.2 \pm 0.1^{\mathrm{a}}$ & $1.1 \pm 0.1^{\mathrm{a}}$ \\
\hline Inguinal FP (g) & $1.4 \pm 0.2^{b}$ & $17.9 \pm 1.1^{a}$ & $18.5 \pm 1.0^{\mathrm{a}}$ & $15.7 \pm 1.0^{\mathrm{a}}$ \\
\hline weight, \%BW & $0.36 \pm 0.0^{b}$ & $2.8 \pm 0.2^{a}$ & $2.6 \pm 0.1^{a}$ & $2.5 \pm 0.1^{a}$ \\
\hline
\end{tabular}

Values are means $\pm \mathrm{SEM}, \mathrm{n}=8$. Means in the same raw with different symbol are significantly different as compared to obese control; ${ }^{*} \mathrm{P}<0.05,{ }^{* * \mathrm{P}}<0.01,{ }^{* * *} \mathrm{P}$ $<0.001$. Means in the same raw with different letter are significantly different among control (lean and obese) and obese treated groups (CLA and VA+CLA).

$\mathrm{FP}^{1}=$ Fat pad

tissue after feeding either CLA or VA+CLA diets as compared to lean and obese rats fed the CD. Interestingly, the citrate synthase activity in liver and adipose tissue did not differ between lean and obese rats fed the CD ( $>$ > 0.05).

Fatty acid profile in epididymal adipose tissue triglyceride The fatty acid composition in adipose tissue triglyceride was shown to directly reflect the dietary fatty acid composition as shown in Table 3 . Obese rats fed with the CLA and VA+CLA diets had a markedly increased proportion of the cis-9, trans-11 CLA isomer relative to the obese control group. The content of this isomer, expressed as a percentage of total fatty acids was different between the treated groups. The CLA diet showed the greatest incorporation of the cis-9, trans-11 CLA isomer (70 fold greater than control group) compared to the VA+CLA diet, which was only 46 fold higher than the obese control group. Rats fed VA+CLA diet showed a greater incorporation of trans-11 18:1 (VA) compared to CLA and obese control rats $(\mathrm{p}<0.001)$. Interestingly, rats fed the $\mathrm{VA}+\mathrm{CLA}$ diet had lower proportions of linoleic acid (18:2 n6), $\alpha$-linolenic acid (18:3 n3) and arachidonic acid (20:4 n6).

\section{Fasting plasma lipid, glucose and insulin concentrations}

As shown in Table 4, fasting plasma TG, TC and LDL-C were significantly lower in obese rats fed either the CLA or the VA+CLA diet, as compared to the CD. However, feeding the VA+CLA diet further reduced plasma NEFA concentration relative to the CLA fed rats and lowered TG and LDL-C concentrations not different from lean rats fed the CD ( $\mathrm{p}>0.05)$. The CLA or VA+CLA diet lowered fasting insulin to that comparable of lean rats $(\mathrm{p}>0.05)$ and reduced total insulin concentration (AUC) after the MTT $(\mathrm{p}<0.05)$. There was no

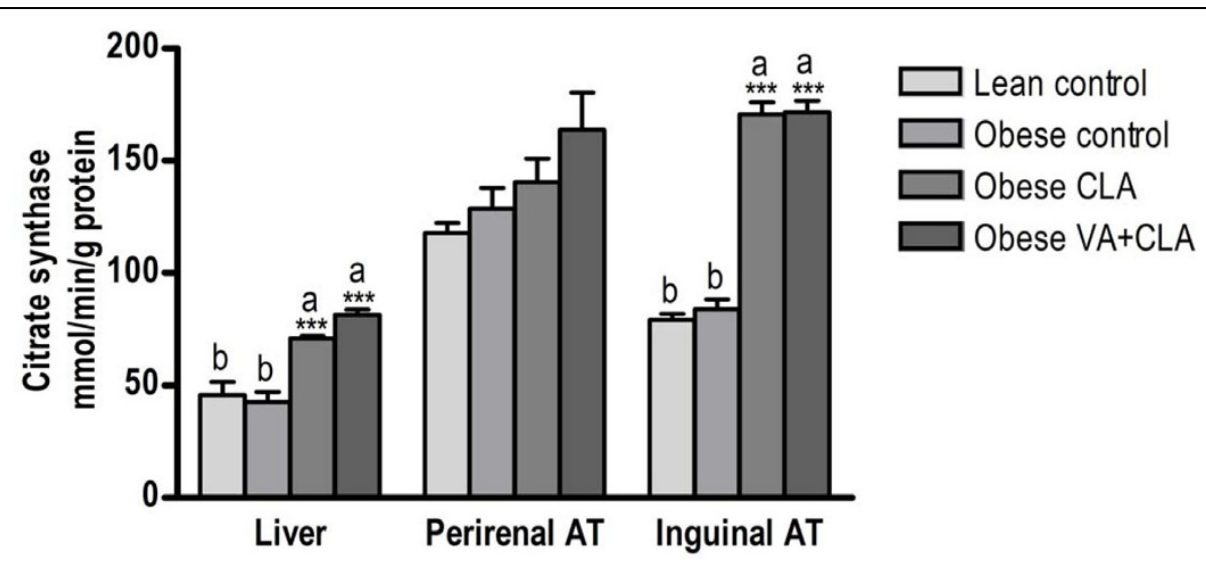

Figure 1 Citrate synthase activity in liver, perirenal and inguinal adipose tissue. Values are mean \pm SEM, $n=8$. Means with different symbol are significantly different as compared to obese control; ${ }^{*} P<0.05,{ }^{* *} \mathrm{P}<0.01$, ${ }^{* * *} \mathrm{P}<0.001$. Means with different letter are significantly different among control (lean and obese) and obese treated groups (CLA and VA+CLA). AT, adipose tissue. 
Table 3 Fatty acid composition (\% of total fatty acids) of triglyceride in epididymal adipose tissue

\begin{tabular}{|c|c|c|c|c|}
\hline & \multicolumn{4}{|c|}{ Dietary groups } \\
\hline & Lean control & Obese control & Obese CLA & Obese VA+CLA \\
\hline \multicolumn{5}{|l|}{ Fatty acid } \\
\hline C18:0 & $13.91 \pm 0.71^{a}$ & $6.36 \pm 0.14^{b}$ & $5.47 \pm 0.07^{b}$ & $6.31 \pm 0.17^{b}$ \\
\hline C18:1 t-11 (VA) & $0.05 \pm 0.01^{b}$ & $0.02 \pm 0.00^{b}$ & $0.08 \pm 0.00^{\mathrm{b}}$ & $1.72 \pm 0.06^{* * * a}$ \\
\hline C18:1 c-9 & $28.37 \pm 0.14^{d}$ & $37.9 \pm 0.56^{\mathrm{a}}$ & $32.72 \pm 0.32^{* * * c}$ & $35.21 \pm 0.49^{* \mathrm{~b}}$ \\
\hline C18:2 n6 & $35.76 \pm 0.22^{\mathrm{a}}$ & $20.51 \pm 0.24^{b}$ & $20.15 \pm 0.25^{b}$ & $15.06 \pm 0.52^{* * * c}$ \\
\hline C18:3 n3 & $1.2 \pm 0.03^{\mathrm{a}}$ & $0.91 \pm 0.02^{b}$ & $0.96 \pm 0.02^{b}$ & $0.47 \pm 0.06^{* * * c}$ \\
\hline CLA c-9, t-11 & $0.05 \pm 0.01^{c}$ & $0.04 \pm 0.01^{c}$ & $2.85 \pm 0.04^{* * * a}$ & $1.91 \pm 0.09^{* * * b}$ \\
\hline C20:4 n6 & $0.45 \pm 0.01^{\mathrm{a}}$ & $0.33 \pm 0.25^{b}$ & $0.32 \pm 0.01^{b}$ & $0.22 \pm 0.0^{* * c}$ \\
\hline
\end{tabular}

Values are mean $\pm S E M, n=8$. Means in the same raw with different symbol are significantly different as compared to obese control; ${ }^{*} P<0.05$, ** $<0.01$,

${ }^{* * *} \mathrm{P}<0.001$. Means in the same raw with different letter are significantly different among control (lean and obese) and obese treated groups (CLA and VA+CLA). Long chain n3 PUFA were not detectable.

statistical difference between groups for either glucose metabolism (fasting or iAUC) or the relative change (iAUC) in insulin.

\section{Post-prandial plasma TG response}

Obese rats had a higher post-prandial plasma TG response (iAUC) compared to lean rats following an OFC (Figure 2). AUC analysis showed an improved total TG concentration $(\mathrm{p}<0.05)$ over the 10 -h post-prandial period in rats fed either the CLA or VA+CLA diet (35 \pm 5 and $38 \pm 8 \mathrm{mmol} / \mathrm{L} . \mathrm{h}$, respectively), compared to obese rats fed the CD $(62 \pm 5 \mathrm{mmol} / \mathrm{L} . \mathrm{h})$. However, the post-prandial iAUC for TG was not different between obese control and obese treatment groups (CLA and VA + CLA).

\section{Liver TG concentration and relative abundance of hepatic lipogenic enzymes}

Liver TG concentration was higher in obese control rats compared to lean control rats. However, feeding the CLA diet resulted in a liver triglyceride concentration that was $22 \%$ lower than the obese rats fed the CD
(Table 4). Interestingly, the VA+CLA diet further lowered liver TG concentration by $43 \%$ and $27 \%$ as compared to obese control and CLA groups, respectively. In addition, CLA and VA+CLA diets resulted in significantly lower hepatic ACC-1 protein abundance relative to obese control (34\% and $38 \%$, respectively) and was normalized to concentrations similar to lean rats fed the $\mathrm{CD}(\mathrm{p}>0.05)$ (Figure 3A, B). The relative abundance of hepatic FAS protein did not differ between the obese groups $(\mathrm{p}>0.05)$ (Figure $3 \mathrm{~A}, \mathrm{C})$.

\section{Discussion}

\section{Combination of VA+CLA increases food intake and} decreases liver weight

Dyslipidemia and insulin resistance are common features associated with cardiovascular disease and the metabolic syndrome. The homozygous obese $(c p / c p)$, JCR:LA- $c p$ rat, has a complete absence of the leptin receptor. As a consequence, the JCR:LA-cp rat spontaneously develops hyperphagia and obesity, associated dyslipidemia, insulin resistance, and macro-and microvascular dysfunction [34-36]. In the present study, we

Table 4 Fasting plasma lipid concentrations, glucose and insulin AUC after MTT and hepatic TG

\begin{tabular}{|c|c|c|c|c|}
\hline & \multicolumn{4}{|c|}{ Dietary groups } \\
\hline & Lean control & Obese control & Obese CLA & Obese VA+CLA \\
\hline $\mathrm{TG}(\mathrm{mmol} / \mathrm{L})$ & $0.47 \pm 0.0^{c}$ & $3.28 \pm 0.4^{a}$ & $2.05 \pm 0.3^{* b}$ & $1.4 \pm 0.1^{* * * b c}$ \\
\hline NEFA (mmol/L) & $0.20 \pm 0.02^{c}$ & $0.48 \pm 0.02^{\mathrm{ab}}$ & $0.57 \pm 0.03^{a}$ & $0.42 \pm 0.05^{b}$ \\
\hline $\mathrm{TC}(\mathrm{mmol} / \mathrm{L})$ & $2.26 \pm 0.0^{c}$ & $6.18 \pm 0.4^{\mathrm{a}}$ & $4.22 \pm 0.2^{* * * b}$ & $4.92 \pm 0.2^{* * b}$ \\
\hline LDL-C (mmol/L) & $0.97 \pm 0.1^{c}$ & $2.28 \pm 0.2^{a}$ & $1.56 \pm 0.1^{* \mathrm{*b}}$ & $1.2 \pm 0.1^{* * * b c}$ \\
\hline Fasting glucose (mmol/L) & $5.94 \pm 0.08$ & $6.81 \pm 0.4$ & $5.94 \pm 0.36$ & $6.75 \pm 0.72$ \\
\hline Glucose iAUC (mmol/L.h) & $45.19 \pm 4.5$ & $52.22 \pm 7.8$ & $70.25 \pm 14.7$ & $42.7 \pm 33.05$ \\
\hline Fasting insulin $(\mu \mathrm{lU} / \mathrm{L})$ & $73.41 \pm 27.4^{b}$ & $629.2 \pm 165.3^{a}$ & $216 \pm 13.6^{* b}$ & $372.8 \pm 98.24^{a b}$ \\
\hline Insulin AUC ( $\mu \mid \cup / L . h)$ & $8739 \pm 1566^{c}$ & $40437 \pm 4384^{a}$ & $24548 \pm 3465^{* b}$ & $23001 \pm 2744^{* b}$ \\
\hline Insulin iAUC ( $\mu \mid \cup / L . h)$ & $4452 \pm 1464$ & $11805 \pm 7603$ & $11585 \pm 3885$ & $4451 \pm 3015$ \\
\hline Liver TG (mmol/g protein) & $2.2 \pm 0.3^{d}$ & $21.2 \pm 1.0^{\mathrm{a}}$ & $16.6 \pm 1.1^{* b}$ & $12.1 \pm 1.3^{* * * c}$ \\
\hline
\end{tabular}

Plasma lipid and liver TG values are mean $\pm S E M, n=8$. Insulin AUC is mean $\pm S E M, n=4$. Means in the same raw with different symbol are significantly different as compared to obese control; ${ }^{*} \mathrm{P}<0.05,{ }^{* *} \mathrm{P}<0.01$, ${ }^{* * *} \mathrm{P}<0.001$. Means in the same raw with different letter are significantly different among control (lean and obese) and obese treated groups (CLA and VA+CLA). 


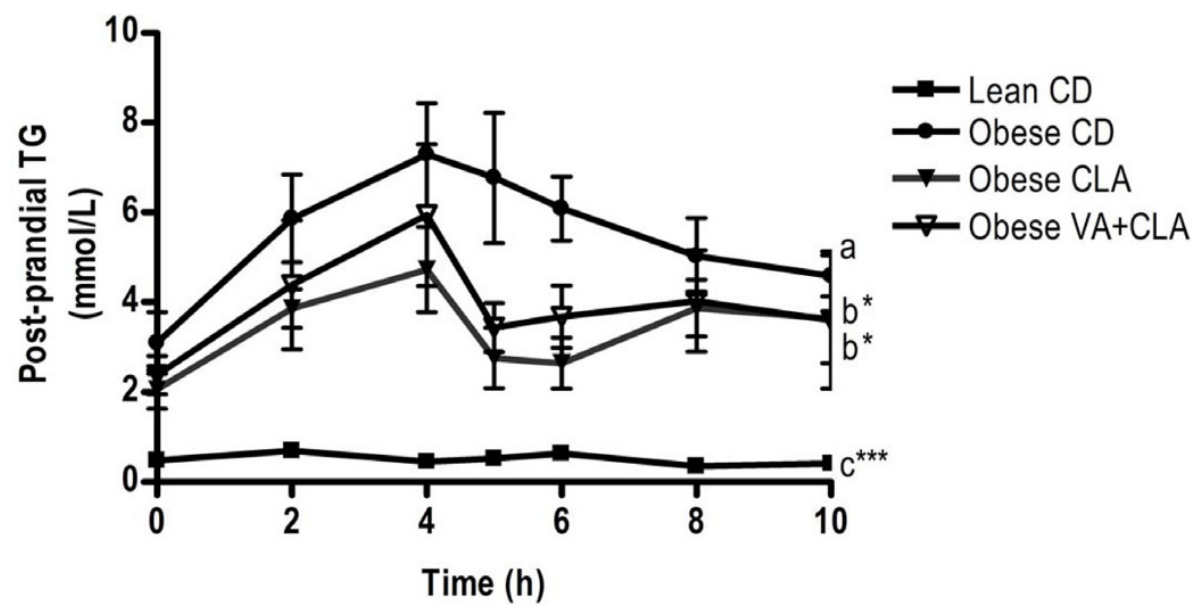

Figure 2 Post-prandial triglyceride response following an oral fat challenge. Values are mean $\pm S E M, n=4$. AUC differ relative to obese rats fed the $C D ;{ }^{b} P<0.05,{ }^{C} P<0.001$. iAUC differ relative to obese rats fed the $C D ;{ }^{* *} P<0.001$.

used this unique animal model to evaluate hypolipidemic effects of cis-9, trans-11 CLA in combination with VA. Obese rats fed the CLA diet had a higher final body weight relative to obese control rats. However, this was not associated with an increase in fat deposition. Cis-9, trans-11 CLA has been observed to regulate metabolic pathways involved in fatty acid oxidation as well as energy production and thermogenesis [37-40]; therefore we investigated whether combination VA +CLA might promote fatty acid oxidation.

\section{CLA and VA+CLA promote mitochondrial fatty acid oxidation in liver and adipose tissue}

Peroxisome proliferator-activated receptor (PPAR)-agonists, such as thiazolidenediones (TZDs), are effective drugs for the treatment of type 2 diabetes by inducing adipogenesis as well as increasing the uptake and metabolism of free fatty acids in adipose tissue. Increased mitochondrial oxidative capacity of white adipose tissue has been observed after treatment with TZD [41,42]. CLA is a natural PPAR ligand [43-45] and has been observed to promote fatty acid oxidation [40] or TG synthesis in adipose tissue contributing to lower circulating NEFA and TG concentrations [7]. We observed a significant increase in citrate synthase activity in liver and inguinal adipose tissue following supplementation with either CLA or VA+CLA diet but not in perirenal adipose tissue. Interestingly, citrate synthase activity was not different between lean and obese control rats. It has been reported that insulin resistance is associated with an increase in muscle mitochondrial content and oxidative capacity [46-48]. Similarly, it has been demonstrated that mitochondrial biogenesis increases during adipose tissue differentiation [49]. Therefore, it can be proposed that JCR:LA-cp rats maintain similar mitochondrial fatty acid oxidation relative to lean rats but during increased dietary lipid consumption, it is insufficient to prevent TG deposition. Treatment with CLA or VA+CLA may stimulate mitochondrial fatty acid oxidation and in turn this may contribute to improvements in liver and adipose tissue metabolism in the JCR:LA-cp rat.

\section{Incorporation of CLA and VA in adipose tissue triglyceride}

It is well established that the fatty acid composition of adipose tissue is dependent on dietary intake. However, endogenous synthesis of fatty acids, fatty acid transport and inter-conversion processes (elongation and desaturation) are also significant contributing factors to the composition of adipose tissue [50]. As expected, supplementation with cis-9, trans-11 CLA (CLA diet) and VA (VA+CLA diet) increased the proportion of these fatty acids in adipose tissue from obese rats. We also wish to note that the endogenous synthesis of cis-9, trans-11 CLA from VA may have also occurred in this study. In both humans and animals, the conversion of dietary VA to CLA has been reported to be at a rate of approximately $12-19 \%$ [ 12 and 14$]$. We also note that the dietary ratio of VA:CLA in this study was $\sim 1.5: 1$, respectively (Table 1 ) and that the resultant incorporation of these fatty acids into adipose tissue was found to be 1:1 following supplementation (Table 3). While we cannot infer a rate of conversion from VA to CLA per se from this data, it would support that previously published.

\section{Combined dietary VA+CLA has a greater effect to reduce dyslipidemia and hepatic steatosis}

One of the most striking effects of the combined treatment $(\mathrm{VA}+\mathrm{CLA})$ in the present study was the reduction 


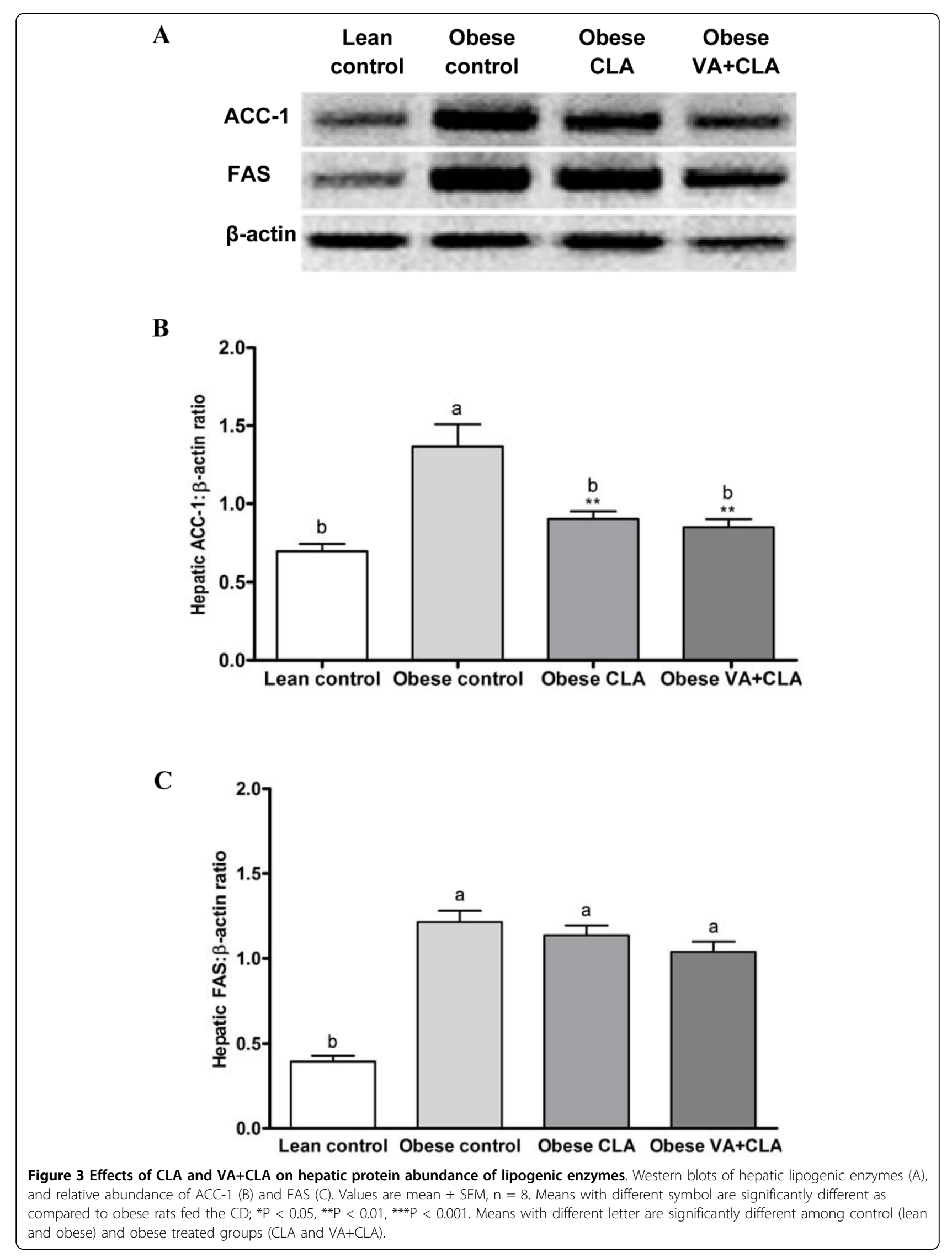


in hepatic TG concentration. The improvement in fasting lipid parameters by VA+CLA diet (i.e. TG and LDLC) suggest an additional benefit with the combination diet and is consistent with previous observations that dietary VA has lipid lowering properties independent from CLA [15]. We also wish to note that both diets (CLA and VA+CLA) consistently contained $0.15 \mathrm{w} / \mathrm{w}$ of the trans-10, cis-12 CLA isomer, which is also known for its hypolipidemic properties.

ACC-1 and FAS are two key lipogenic enzymes involved in the synthesis of fatty acids and subsequent TG synthesis. TG is then either stored as lipid droplets within the hepatocyte, secreted into the blood compartment as VLDL or hydrolyzed via oxidation [51]. It is plausible that reduced hepatic lipogenesis may contribute (at least in part) to reduced hepatic TG in rats fed either the CLA or VA+CLA diet, which is supported by a lower hepatic ACC-1 protein abundance relative to obese rats fed the $C D$. We have reported previously that VA may act in part via ACC-1 and FAS pathways resulting in reduced VLDL secretion to decrease circulating concentrations of plasma TG and LDL-C [15]. However, in conditions of insulin resistance, hepatic steatosis is thought to be caused by an increased free fatty acid flux from adipose tissue into the liver [52]. As discussed above, rats fed the combined treatment (VA+CLA) showed lower circulating NEFA concentrations compared to rats fed the CLA diet alone. We propose that reduced NEFA may also contribute to a further decrease in hepatic TG. In addition, activation of ACC is regulated by phosphorylation/dephosphorylation [53] and thus, it may be possible that CLA and VA+CLA diets may differently regulate post-translational modifications of ACC-1.

\section{Conclusion}

In conclusion, results in this study confirm hypolipidemic effects of chronic supplementation with cis-9, trans-11 CLA alone or in combination with trans-11 VA in the dyslipidemic and insulin resistant JCR:LA-cp rat. Our data also support the hypothesis that a dietary formulation enriched with both CLA and VA may further enhance their hypolipidemic properties, particularly during conditions of hypertriglyceridemia, hypercholesterolemia and/or hepatic steatosis.

\section{Additional material}

Additional file 1: Changes in body weight throughout the study and schematic representation of the experimental design. Rats ( $n=$ 8) were fed a standard chow diet prior to the study (from 3-8 wk of age). Then, control and experimental diets were provided for 16 wk. An oral fat challenge test (OFC) and a meal tolerance test (MTT) were conducted on different rats ( $n=4$ in each test).

\section{List of abbreviations}

ACC-1: acetyl-CoA carboxylase-1; AUC: area under the curve; iAUC: incremental area under the curve; CD: control diet; CLA: cis-9, trans-11 CLA FAS: fatty acid synthase; MTT: meal tolerance test; NEFA: nonesterified fatty acid; OFC: oral fat challenge; TC: total cholesterol; TG: triglyceride; VA: trans11 vaccenic.

\section{Acknowledgements}

We thank Kristina MacNaughton, Sue Goruk and Sharon Sokolik for their excellent technical assistance associated with this project.

\section{Author details}

${ }^{1}$ Metabolic and Cardiovascular Diseases Laboratory, University of Alberta, Edmonton, AB, T6G 2P5, Canada. ${ }^{2}$ Alberta Institute for Human Nutrition, University of Alberta, Edmonton, AB, T6G 2P5, Canada. ${ }^{3}$ Alberta Diabetes Institute, University of Alberta, Edmonton, AB, T6G 2P5, Canada. ${ }^{4}$ Department of Applied Microbiology and Food Science, University of Saskatchewan, Saskatoon, SK, S7N 5A8, Canada.

\section{Authors' contributions}

MMJS, JL, CJF, DFV, and SDP contributed to research design; MJR and JS provided essential reagents; MMJS, JL, YW, MRR and DCW conducted research and analyzed data; MMJS, CJF, DFV, and SDP contributed to the writing of the manuscript; MMJS and SDP had primary responsibility for the final content. All authors read and approved the final manuscript.

\section{Competing interests}

Funds for this work were supported in part by the Dairy Farmers of Canada, Alberta Livestock Industry Development Fund and the Natural Science and Engineering Research Council of Canada. MMJS is supported by a scholarship from the National Council of Mexico for Science and Technology (CONACYT). SDP is supported by a New Investigator Award from HSFC.

The authors declare that they have no competing interests.

Received: 1 April 2010 Accepted: 16 July 2010 Published: 16 July 2010

\section{References}

1. Wahle KW, Heys SD, Rotondo D: Conjugated linoleic acids: are they beneficial or detrimental to health? Prog Lipid Res 2004, 43:553-87.

2. Bhattacharya A, Banu J, Rahman M, Causey J, Fernandes G: Biological effects of conjugated linoleic acids in health and disease. J Nutr Biochem 2006, 17:789-810.

3. Taylor CG, Zahradka P: Dietary conjugated linoleic acid and insulin sensitivity and resistance in rodent models. Am J Clin Nutr 2004, 79(suppl):1164S-1168S.

4. Terpstra AHM: Effect of conjugated linoleic acid on body composition and plasma lipids in human: an overview of the literature. Am J Clin Nutr 2004, 79:352-361.

5. Tricon S, Burdge GC, Williams CM, Calder PC, Yaqoob P: The effects of conjugated linoleic acid on human health-related outcomes. Proc Nutr Soc 2005, 64:171-182.

6. Park Y, Pariza MW: Mechanisms of body fat modulation by conjugated linoleic acid (CLA). Food Res Int 2007, 40:311-323.

7. Roche HM, Noone E, Sewter C, Mc Bennett S, Savage D, Gibney MJ, O'Rahilly S, Vidal-Puig AJ: Isomer-dependent metabolic effects of conjugated linoleic acid: insights from molecular markers sterol regulatory element-binding protein-1c and LXRalpha. Diabetes 2002, 51:2037-2044

8. Risérus U, Basu S, Jovinge S, Fredrikson GN, Ärnlöv J, Vessby B: Supplementation with conjugated linoleic acid causes isomerdependent oxidative stress and elevated C-Reactive Protein. A potential link to fatty acid-induced insulin resistance. Circulation 2002, 106:1925-1929.

9. Javadi M, Beynen AC, Hovenier R, Lankhorst A, Lemmens AG, Terpstra AHM Geelen MJH: Prolonged feeding of mice with conjugated linoleic acid increases hepatic fatty acid synthesis relative to oxidation. J Nutr Biochem 2004, 15:680-687.

10. Cooper MH, Miller JL, Mitchell PL, Currie DL, McLeod RS: Conjugated linoleic acid isomers have no effect on atherosclerosis and adverse 
effects on lipoprotein and liver lipid metabolism in apoE-/-mice fed a high cholesterol diet. Atherosclerosis 2008, 200:294-302.

11. Mendis S, Cruz-Hernandez C, Ratnayake WMN: Fatty acid profile of Canadian dairy products with special attention to the transoctadecenoic acid and conjugated linoleic acid isomers. J AOAC Int 2008, 9:811-819

12. Santora JE, Palmquist DL, Roehrig KL: Trans-vaccenic acid is desaturated to conjugated linoleic acid in mice. J Nutr 2000, 130:208-215.

13. Corl BA, Barbano DM, Bauman DE, Ip C: Cis-9, trans-11 CLA derived endogenously from trans-11 18:1 reduces cancer risk in rats. J Nutr 2003, 133:2893-2900

14. Turpeinen AM, Mutanen M, Aro A, Salminen I, Basu S, Palmquist DL, Griinari JM: Bioconversion of vaccenic acid to conjugated linoleic acid in humans. Am J Clin Nutri 2002, 76:504-510.

15. Wang Y, Jacome-Sosa MM, Ruth MR, Goruk SD, Reaney MJ, Glimm DR, Wright DC, Vine DF, Field CF, Proctor SD: Trans-11 vaccenic acid reduces hepatic lipogenesis and chylomicron secretion in JCR: LA-cp rats. J Nutr 2009, 139:2049-2054

16. Wang Y, Lu J, Ruth MR, Goruk SD, Reaney MJ, Glimm DR, Vine DF, Field CF, Proctor SD: Trans-11 vaccenic acid dietary supplementation induces hypolipidemic effects in JCR:LA-cp rats. J Nutr 2008, 138:2117-2122.

17. Tholstrup T, Raff M, Basu S, Nonboe P, Sejrsen K, Straarup EM: Effects of butter high in ruminant trans and monounsaturated fatty acids on lipoproteins, incorporation of fatty acids into lipid classes, plasma Creactive protein, oxidative stress, hemostatic variables, and insulin in healthy young men. Am J Clin Nutr 2006, 83:237-43.

18. Motard-Belanger A, Charest A, Grenier G, Paquin P, Chouinard Y, Lemieux $S$, Couture P, Lamarche B: Study of the effect of trans fatty acids from ruminants on blood lipids and other risk factors for cardiovascular disease. Am J Clin Nutr 2008, 87:593-9.

19. Chardigny JM, Destaillats F, Malpuech-Brugère C, Moulin J, Bauman DE, Lock AL, Barbano DM, Mensink RP, Bezelgues JB, Chaumont P, Combe N, Cristiani I, Joffre F, German JB, Dionisi F, Boirie Y, Sébédio JL: Do trans fatty acids from industrially produced sources and from natural sources have the same effect on cardiovascular disease risk factors in healthy subjects? Results of the trans Fatty Acids Collaboration (TRANSFACT) study. Am J Clin Nutr 2008, 87:558-66.

20. Lock AL, Horne CAM, Bauman DE, Salter AM: Butter naturally enriched in conjugated linoleic acid and vaccenic acid alters tissue fatty acids and improves the plasma lipoprotein profile in cholesterol-fed hamsters. J Nutr 2005, 135:1934-1939.

21. Roy A, Chardigny JM, Bauchart D, Ferlay A, Lorenz S, Durand D, Gruffat D, Faulconnier Y, Sébédio J-L, Chilliard Y: Butters rich either in trans-10-C18:1 or in trans-11-C18:1 plus cis-9, trans-11 CLA differentially affect plasma lipids and aortic fatty streak in experimental atherosclerosis in rabbits. Animal 2007, 1:467-476.

22. Bauchart D, Roy A, Lorenz $S$, Chardigny JM, Ferlay A, Gruffat D, Sébédio JL, Chilliard Y, Durand D: Butters varying in trans 18:1 and cis-9, trans11 conjugated linoleic acid modify plasma lipoproteins in the hypercholesterolemic rabbit. Lipids 2007, 42:123-33.

23. Tyburczy C, Major C, Lock AL, Destaillats F, Lawrence P, Brenna JT, Salter AM, Bauman DE: Individual trans octadecenoic acids and partially hydrogenated vegetable oil differentially affect hepatic lipid and lipoprotein metabolism in golden syrian hamsters. J Nutr 2009, 139:257-263.

24. Bassett CMC, Edel AL, Patenaude AF, McCullough RS, Blackwood DP, Chouinard PW, Paquin P, Lamarche B, Pierce GN: Dietary Vaccenic Acid Has Antiatherogenic Effects in LDLr ${ }^{-1-}$ Mice. J Nutr 2010, 140:18-24

25. Bauman DE, Barbano DM, Dwyer DA, Griinari JM: Technical note: Production of butter with enhanced conjugated linoleic acid for use in biomedical studies with animal models. J Dairy Sci 2000, 83:2422-2425.

26. Lock AL, Bauman DE: Modifying milk fat composition of dairy cows to enhance fatty acids beneficial to human health. Lipids 2004 39:1197-1206.

27. Jones EL, Kohen C, Jones AK, Lupoli B, Grandison AS, Beever DE, Williams CM, Calder PC, Yaqoob P: Chemical, physical, and sensory properties of dairy products enriched with conjugated linoleic acid. $J$ Dairy Sci 2005, 88:2923-2937.

28. Cruz-Hernandez C, Kramer JKG, Kennelly JJ, Glimm DR, Sorensen BM, Okine EK, Goonewardene LA, Weselake RJ: Evaluating the conjugated linoleic acid and trans 18:1 isomers in milk fat of dairy cows fed increasing amounts of sunflower oil and a constant level of fish oil. $J$ Dairy Sci 2007, 90:3786-3801.

29. Vine DF, Takechi R, Russell JC, Proctor SD: Impaired postprandial apolipoprotein-B48 metabolism in the obese, insulin-resistant JCR:LA- $c p$ rat: increased atherogenicity for the metabolic syndrome. Atherosclerosis 2007, 190:282-290.

30. Russell JC, Ahuja SK, Manickavel V, Rajotte RV, Amy RM: Insulin resistance and impaired glucose tolerance in the atherosclerosis-prone LA/N corpulent rat. Arteriosclerosis 1987, 7:620-626.

31. Raff M, Tholstrup T, Sejsen K, Straarup EM, Wijnberg N: Diets rich in conjugated linoleic acid and vaccenic acid have no effect on blood pressure and isobaric arterial elasticity in healthy young men. $J$ Nutr 2006, 136:992-997.

32. Swain MLBB: Formation of traces of conjugated tetraenoic and trienoic constitutents in autoxidized linolenic and linoleic acids and vegetable oils during alkali-isomerization. JAOCS 1949, 26:272-277.

33. Qin Y, Dalen KT, Gustafsson JA, Nebb HI: Regulation of hepatic fatty acid elongase 5 by LXRalpha-SREBP-1c. Biochim Biophys Acta 2009, 1791:140-147.

34. Russell JC, Proctor SD: Small animal models of cardiovascular disease: tools for the study of the roles of metabolic syndrome, dyslipidemia, and atherosclerosis. Cardiovasc Pathol 2006, 15:318-330.

35. Elam MB, Wilcox HG, Cagen LM, Deng X, Raghow R, Kumar P, Heimberg M, Russell JC: Increased hepatic VLDL secretion, lipogenesis, and SREBP-1 expression in the corpulent JCR:LA-cp rat. J Lipid Res 2001, 42:2039-2048,

36. Kelly SE, Proctor SD: The JCR:LA-cp Rat: An animal model of the metabolic syndrome exhibiting micro-and macro-vascular disease. Animal Models of Diabetes Boca Raton: CRC PressShafrir E , 2 2007, 157-183.

37. Choi JS, Jung MH, Park HS, Song J: Effect of conjugated linoleic acid isomers on insulin resistance and mRNA levels of genes regulating energy metabolism in high-fat-fed rats. Nutrition 2004, 20:1008-1017.

38. Ryder JW, Portocarrero CP, Song XM, Cui L, Yu M, Combatsiaris T, Galuska D, Bauman DE, Barbano DM, Charron MJ, Zierath JR, Houseknecht KL: Isomer-specific antidiabetic properties of conjugated linoleic acid improved glucose tolerance, skeletal muscle insulin action, and UCP-2 gene expression. Diabetes 2001, 50:1149-1157.

39. Rodriguez E, Ribot J, Palou A: Trans-10, cis-12, but not cis-9, trans-11 CLA isomer, inhibits brown adipocyte thermogenic capacity. Am J Physiol Regulatory Integrative Comp Physiol 2002, 282:R1789-R1797.

40. Choi JS, Koh I, Jung MH, Song J: Effects of three different conjugated linoleic acid preparations on insulin signalling, fat oxidation and mitochondrial function in rats fed a high-fat diet. Brit J Nutr 2007, 98:264-275.

41. Bogacka I, Xie H, Bray GA, Smith SR: Pioglitazone induces mitochondrial biogenesis in human subcutaneous adipose tissue in vivo. Diabetes 2005, 54:1392-1399.

42. Rong JX, Qiu Y, Hansen MK, Zhu L, Zhang V, Xie M, Okamoto Y, Mattie MD, Higashiyama H, Asano S, Strum JC, Ryan TE: Adipose mitochondrial biogenesis is suppressed in $d b / d b$ and high-fat diet-fed mice and improved by rosiglitazone. Diabetes 2007, 56:1751-1760.

43. Moya-Camarena AY, Vanden-Heuvel JP, Blanchard SG, Leesnitzer LA, Belury MA: Conjugated linoleic acid is a potent naturally occurring ligand and activator of PPAR $\alpha$. J Lipid Res 1999, 40:1426-1433.

44. Wargent E, Sennitt MV, Stocker C, Mayes AE, Brown L, O'dowd J, Wang S, Einerhand AW, Mohede I, Arch JRS, Cawthorne MA: Prolonged treatment of genetically obese mice with conjugated linoleic acid improves glucose tolerance and lowers plasma insulin concentration: possible involvement of PPAR activation. Lipids Health Dis 2005, 4:3-16.

45. Brown JM, Boysen MS, Jensen SS, Morrison RF, Storkson J, Lea-Currie R, Pariza M, Mandrup S, McIntosh MK: Isomer-specific regulation of metabolism and PPAR gamma signaling by CLA in human preadipocytes. J Lipid Res 2003, 44:1287-300

46. Turner N, Bruce CR, Beale SM, Hoehn KL, So T, Rolph MS, Cooney GJ: Excess lipid availability increases mitochondrial fatty acid oxidative capacity in muscle: evidence against a role for reduced fatty acid oxidation in lipid-induced insulin resistance in rodents. Diabetes 2007, 56:2085-2092.

47. Hancock CR, Han DH, Chen M, Terada S, Yasuda T, Wright DC, Holloszy JO: High-fat diets cause insulin resistance despite an increase in muscle mitochondria. Proc Natl Acad Sci USA 2008, 105:7815-7820. 
48. Hoeks J, Briedé JJ, de V ogel J, Schaart G, Nabben M, Moonen-Kornips E, Hesselink MK, Schrauwen P: Mitochondrial function, content and ROS production in rat skeletal muscle: effect of high-fat feeding. FEBS let 2008, 582:510-516.

49. Wilson-Fritch L, Burkart A, Bell G, Mendelson K, Leszyk J, Nicoloro S, Czeck M, Corvera S: Mitochondrial biogenesis and remodeling during adipogenesis and in response to the insulin sensitizer rosiglitazone. Mol Cell Biol 2003, 23:1085-1094.

50. Hodson L, Skeaff CM, Fielding BA: Fatty acid composition of adipose tissue and blood in humans and its use as a biomarker of dietary intake. Progress in Lipid Research 2008, 47:348-380

51. Postic C, Girard J: The role of the lipogenic pathway in the development of hepatic steatosis. Diabetes \& Metabolism 2008, 34:643-648.

52. Lewis GF, Carpentier A, Adeli K, Giacca A: Disordered fat storage and mobilization in the pathogenesis of insulin resistance and type 2 diabetes. Endocr Rev 2002, 23:201-229.

53. Abu-Elheiga L, Brinkley WR, Zhong L, Chirala SS, Wakil SJ: The subcellular localization of acetyl-CoA carboxylase 2. Proc Natl Acad Sci USA 2000, 97:1444-1449.

doi:10.1186/1743-7075-7-60

Cite this article as: Jacome-Sosa et al:: Increased hypolipidemic benefits of cis-9, trans-11 conjugated linoleic acid in combination with trans-11 vaccenic acid in a rodent model of the metabolic syndrome, the JCR: LA-cp rat. Nutrition \& Metabolism 2010 7:60

\section{Submit your next manuscript to BioMed Central and take full advantage of:}

- Convenient online submission

- Thorough peer review

- No space constraints or color figure charges

- Immediate publication on acceptance

- Inclusion in PubMed, CAS, Scopus and Google Scholar

- Research which is freely available for redistribution

Submit your manuscript at www.biomedcentral.com/submit 